\title{
PENGARUH BRAND AWARENESS, BRAND IMAGE DAN BRAND LOYALTY TERHADAP BRAND EQUITY PADA PENGGUNA SEPATU NIKE DI JAKARTA
}

\author{
Juliana \\ Program Studi Magister Manajemen Universitas Tarumanagara \\ juliana.kie@hotmail.com
}

\begin{abstract}
The aim of this study are: First, to explore the effect of brand awareness towards brand equity. Second, to explore the effect of brand image towards brand equity. Third, to explore brand loyalty towards brand equity. The method of data collection is convenience sampling. The samples of this research are collected from 165 respondent, who used Nike shoes in Jakarta. The technique of data analysis used in this study was multiple regression analysis via the Statistical Package for Social Sciences computer programme version 18. The result are: (1) brand awareness has a positive impact toward brand equity; (2) brand image has a positive impact towards brand equity; (3) brand loyalty is the main impact towards brand equity.
\end{abstract}

Keywords : Brand Awareness, Brand Image, Brand Loyalty, Brand Equity

\section{PENDAHULUAN}

Pola hidup sehat saat ini telah menjadi trend di kalangan masyarakat perkotaan dengan rutin menjalankan aktivitas berolahraga. Kegiatan olahraga yang dahulunya hanya dilakukan oleh beberapa kalangan saja, sekarang sudah menjadi kebiasaan yang dilakukan oleh semua lapisan masyarakat. Melihat besarnya antusias masyarakat untuk giat berolahraga, merupakan peluang bagi pengusaha pada bidang industri yang berkaitan dengan perlengkapan olahraga. Tingkat persaingan dalam industri ini semakin tinggi. Hal tersebut dapat terlihat dari banyaknya produsen penyedia perlengkapan olahraga yang ada di dunia seperti nike, adidas, reebok dan merek lainnya yang ada di pasaran. Dengan banyaknya brand yang ada di pasaran, membuat konsumen memiliki banyak pilihan dalam memilih produk yang hendak dibeli mulai dari pertimbangan dari segi harga, desain, kualitas, fitur dan juga brand itu sendiri. Brand bukan sekedar logo atau nama perusahaan, melainkan image atau persepsi seseorang tentang produk atau perusahaan.

Melalui brand yang kuat perusahaan dapat mengelola aset-aset mereka dengan baik, meningkatkan arus kas, memperluas pangsa pasar, menetapkan harga premium, mengurangi biaya promosi, meningkatkan penjualan, menjaga stabilitas, dan meningkatkan keunggulan kompetitif. Brand equity merupakan suatu bentuk respon atau tanggapan dari konsumen terhadap sebuah merek (Simamora, 2003). Ekuitas merek dapat tercermin dalam cara konsumen berpikir, merasa dan bertindak dalam hubungannya dengan merek, dan juga harga, pangsa pasar dan profitabilitas yang diberikan merek untuk perusahaan. Menurut Aaker (1991), banyak faktor yang mempengaruhi brand equity diantaranya adalah brand association, brand loyalty, brand awareness, brand image, perceived quality of brand.

\footnotetext{
${ }^{1}$ Mahasiswa Program Studi Magister Manajemen Universitas Tarumanagara (juliana.kie@hotmail.com)

Persaingan yang semakin ketat membuat perusahaan harus mencari cara agar selalu ada di pasaran. Perusahaan menyadari untuk selalu ada dipasaran konsumen harus sadar akan keberadaan brand mereka. Dengan banyaknya konsumen yang mengenali, mengingat kembali brand, maka membuat brand tersebut menjadi top brand sehingga semakin kuat brand awareness membuat brand equity meningkat dan brand tersebut menjadi kuat di pasaran. (Keller, 1993). Brand image mempresentasikan keseluruhan persepsi terhadap brand
} 
dan dibentuk dari informasi dan pengalaman terhadap brand tersebut. Brand Image yang kuat berhubungan dengan sikap yang berupa keyakinan dan preferensi konsumen terhadap suatu brand yang menjadikan brand equity perusahaan tersebut semakin meningkat. (Setiadi, 2003).

Perusahaan menyadari bahwa brand loyalty merupakan keuntungan bagi perusahaan, karena brand loyalty menjadi aset yang penting bagi perusahaan. Brand Loyalty membuat konsumen akan selalu memilih brand tersebut daripada brand lainnya sehingga semakin kuat brand loyalty akan meningkatkan brand equity. (Dekimpe et al.,1997)

Tujuan dari penelitian ini adalah untuk mengetahui: (1)pengaruh brand awareness terhadap brand equity. (2) pengaruh brand image terhadap brand equity. (3) pengaruh brand loyalty terhadap brand equity. Hasil penelitian ini diharapkan dapat memberikan informasi kepada perusahaan Nike faktor-faktor apa saja yang dapat membantu meningkatkan brand equity, sehingga dapat membantu perusahaan Nike meningkatkan pendapatan perusahaan dan membuat brand Nike semakin tidak tergantikan di pasaran dan menjadikan merek tersebut mempunyai nilai yang kuat dibandingkan kompetitor lainnya.

\section{LANDASAN TEORI}

\section{Brand Awareness}

Menurut Darmadi Durianto, Sugiarto, Tony Simanjuntak (2004:54) menyatakan bahwa "Brand Awareness adalah kesanggupan seorang calon pembeli untuk mengenali, mengingat kembali suatu merek sebagai bagian dari suatu kategori produk." Sementara Eti Rochaety (2005:35) menyatakan bahwa "brand awareness is the ability of a customer to remember a particular brand or specific ad spontaneously or after designed with key words". Dan Kotler (2009:532) menyatakan bahwa brand awareness adalah "the ability to identify the brand under different condition, as reflected by their brand recognition or recall performance". Peneliti menyimpulkan brand awareness adalah kesanggupan seorang calon pembeli untuk mengenali, mengingat kembali suatu merek sebagai bagian dari suatu kategori produk. Menurut Aaker (2000), brand awareness mempunyai urutan tingkatan kesadaran merek dari tingkatan terendah sampai tingkatan tertinggi, yaitu: unaware of brand, brand recognition, brand recall, top of mind. Durianto (2004) menyatakan bahwa brand awareness dapat dibangun dan diperbaiki melalui cara-cara berikut: (1) Pesan yang disampaikan oleh suatu brand harus mudah diingat oleh konsumen. (2) Pesan yang disampaikan harus berbeda dengan produk lainnya serta harus ada hubungan antara brand dengan kategori produknya. (3) Memakai slogan maupun jingle lagu yang menarik sehingga membantu konsumen mengingat brand. (4) Jika suatu brand memiliki simbol, hendaknya simbol tersebut dapat dihubungkan dengan brandnya. (5) Perluasan nama brand dapat dipakai agar brand semakin diingat konsumen. (6) Brand awareness dapat diperkuat dengan memakai suatu isyarat yang sesuai dengan kategori produk, brand, maupun keduanya. (7) Melakukan pengulangan untuk meningkatkan pengingatan, karena membentuk ingatan lebih sulit dibanding membentuk pengenalan.

\section{Brand Image}

Menurut Kotler (2001: 273) brand image adalah "the mental representation of the brand based on individual consumer's beliefs, ideas and impression". Supranto dan Limakrisna (2007:132) juga menyatakan bahwa "brand image ialah apa yang customer pikir atau rasakan ketika mereka mendengar atau melihat nama suatu merek atau pada intinya apa yang customer telah pelajari tentang merek". Sementara Low dan Lamb (2000:352) menyatakan bahwa "Brand image is the reasoned and emotional perceptions of consumers attached to specific brands". Peneliti menyimpulkan brand image adalah apa yang pelanggan pikir atau rasakan ketika mereka mendengar atau melihat nama suatu merek atau pada intinya apa yang customer telah pelajari tentang merek. Menurut Boush dan Jones (dalam Kahle \& 
Kim, 2006) mengemukakan bahwa citra merek (brand image) memiliki beberapa fungsi dan peran, di antaranya adalah Pintu masuk pasar (Market Entry), sumber nilai tambah produk (Source of Added Product Value), penyimpan nilai perusahaan (Corporate Store of Value), kekuatan dalam penyaluran produk (Channel Power).

\section{Brand Loyalty}

Menurut Zaltman (1979:288) Brand loyalty adalah "one type of repeat purchase". Sedangkan menurut Freddy Rangkuti (2009:60) menyatakan bahwa "Loyalitas merek adalah ukuran dari kesetiaan konsumen terhadap suatu merek". Dan Mowen (1995:531) menyatakan bahwa "Brand loyalty is defined as the degree to which a customer holds a positive attitude toward a brand, has a commitment to it, and intends to continue purchasing it in the future". Jadi, brand loyalty adalah tingkatan dimana pelanggan memiliki sikap yang positif terhadap suatu merek, mempunyai komitmen dan cenderung terus melanjutkan pembelian di masa yang akan datang. Menurut Aaker dalam Durianto (2004), dalam kaitannya dengan loyalitas merek suatu produk, didapati adanya beberapa tingkatan loyalitas merek yaitu: switcher (berpindah-pindah), habitual buyer (pembeli yang bersifat kebiasaan), satisfied buyer (pembeli yang puas dengan biaya peralihan), likes the brand (menyukai merek), committed buyer (pembeli yang berkomiten).

\section{Brand Equity}

Menurut Aaker and Joachimsthaler (2000:17) brand equity adalah "as a set of brand assets (or liabilities) linked to a brand's name and symbol that adds to (or subtract from) a product or service". Sedangkan menurut Astuti dan Cahyadi (2007:145) "brand equity adalah seperangkat asosiasi dan perilaku yang dimiliki oleh pelanggan merek, anggota saluran distribusi, dan perusahaan yang memungkinkan suatu merek mendapatkan kekuatan, daya tahan, dan keunggulan yang dapat membedakan dengan merek pesaing”. Dan Tjiptono (2004:38) "Ekuitas merek adalah serangkaian aset dan kewajiban merek yang terkait dengan sebuah merek, nama, dan simbolnya, yang menambah atau mengurangi nilai yang diberikan sebuah produk atau jasa kepada perusahaan dan atau pelanggan perusahaan tersebut". Peneliti berpendapat bahwa brand equity adalah nilai suatu merek berdasarkan seberapa kuat nilai merek tersebut memiliki nilai loyalitas merek, kesadaran konsumen akan merek tersebut, kualitas yang dipersepsikan, asosiasi merek, dan berbagai aset lainnya seperti paten, merek dagang dan hubungan jaringan distribusi. Menurut Feldwick (2005), ada tiga pendekatan berbeda untuk memahami brand equity, yaitu: brand value, brand strength, dan brand description. Brand value biasanya digunakan untuk menjelaskan ekuitas merek dari aspek keuangannya sedangkan brand strength dan brand description adalah aspek-aspek yang digunakan dalam menjelaskan ekuitas merek berdasarkan aspek konsumen.

\section{Pengaruh Brand Awareness terhadap Brand Equity}

Menurut penelitian Muhammad Asif et al. (2015) mengemukakan bahwa brand awareness mempunyai pengaruh yang positif terhadap brand equity, dimana pada penelitian ini juga menunjukkan bahwa kesadaran konsumen terhadap merek tertentu mempunyai dampak yang positif pada brand equity. Hal ini didukung oleh penelitian Torres et al. (2015), dimana brand awareness mempunyai pengaruh yang kuat terhadap brand equity. Berdasarkan paparan diatas, maka hipotesis penelitian adalah sebagai berikut:

H1 : Terdapat pengaruh positif brand awareness terhadap brand equity.

\section{Pengaruh Brand Image terhadap Brand Equity.}

Penelitian yang dilakukan. Lee et al. (2011) juga menemukan bahwa sebuah perusahaan dapat meningkatkan brand equity dengan meningkatkan brand image perusahaan menjadi brand yang lebih baik. Hal serupa juga dijelaskan pada penelitian Serveri dan Ling 
(2013) yang menemukan bahwa brand image mempunyai pengaruh yang positif terhadap brand equity. Berdasarkan paparan diatas, maka hipotesis penelitian adalah sebagai berikut :

$\mathrm{H} 2 \quad$ : Terdapat pengaruh positif brand image terhadap brand equity.

Pengaruh Brand Loyalty terhadap Brand Equity.

Dalam penelitian Torres et al. (2015) juga menunjukkan adanya hubungan yang sangat kuat antara brand loyalty dalam mempengaruhi brand equity, penelitian ini juga menemukan bahwa dalam meningkatkan brand equity perusahaan harus memfokuskan pada brand loyalty. Hal ini didukung oleh penelitian Rios dan Riquelme (2008) yang menyatakan bahwa brand loyalty secara langsung menciptakan brand equity. Berdasarkan paparan diatas, maka hipotesis penelitian adalah sebagai berikut :

H3 : Terdapat pengaruh positif brand loyalty terhadap brand equity.

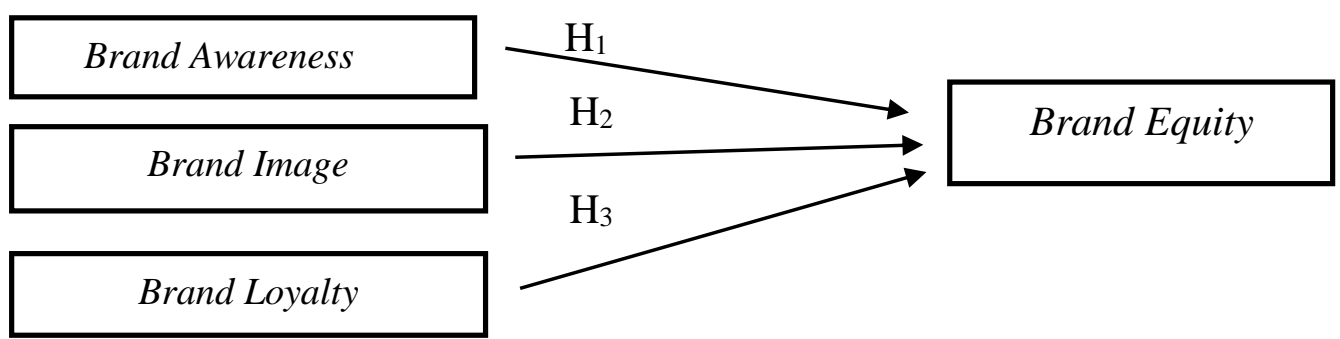

\section{METODOLOGI PENELITIAN}

\section{Populasi dan Metode Pengambilan Sampel.}

Populasi dalam penelitian ini adalah seluruh pengguna Nike. Sampel penelitian adalah seluruh pengguna sepatu Nike di Jakarta. Ukuran sampel yang digunakan pada penelitian ini adalah 165 responden. Metode pengambilan sampel yang digunakan adalah non-probability sampling. Teknik pengambilan sampel yang digunakan adalah convenience sampling. Berdasarkan data yang terkumpul, mayoritas karakteristik responden pada penelitian ini adalah perempuan, berumur 17 - 40 tahun, pendidikan terakhir S1, bekerja sebagi pegawai swasta, memiliki pengeluaran per bulan Rp 3.000.000 - Rp 5.000.000, gemar berolahraga, rutin berolahraga $1-2$ kali dalam seminggu, jenis sepatu yang paling sering dibeli adalah sepatu running, rata-rata mempunyai 1-3 pasang sepatu Nike, dan anggaran untuk membeli sepatu di harga Rp 1.000.000 - Rp 2.000.000.

\section{Variabel dan Pengukuran.}

Pada penelitian ini, variabel brand awareness, brand image dan brand loyalty adalah variabel independen, sedangkan brand equity adalah variabel dependen. Untuk mengukur variabel ini, menggunakan beberapa instrument yang diadaptasi dari studi penelitian terdahulu. Skala pengukuran yang digunakan dalam penelitian ini adalah Likert Type Scale dengan 5 skala denagn 1 menunjukkan "sangat tidak setuju" dan 5 menunjukkan "sangat setuju". Dari hasil uji validitas dan reabilitas menunjukkan bahwa semua variabel yang digunakan pada penelitian ini adalah valid dan reliabel. 
Tabel dibawah ini menunjukkan pengukuran masing-masing variabel dan sumbernya:

Tabel 1. Variabel dan Pengukuran Brand Awareness

\begin{tabular}{|c|c|c|c|}
\hline \multicolumn{2}{|c|}{ Variabel } & Jumlah Item & Sumber \\
\hline 1. & Brand Awareness & 2 & \multirow{3}{*}{ Sasmita et. al (2015) } \\
\hline 2. & Brand Image & 3 & \\
\hline 3. & Brand Loyalty & 5 & \\
\hline 4. & Brand Equity & 2 & $\begin{array}{l}\text { Sasmita et. al (2015), Torres et. al } \\
\text { (2015) }\end{array}$ \\
\hline
\end{tabular}

\section{Metode Analisis Data.}

Metode analis data yang digunakan adalah analisis regresi berganda. Sedangkan untuk uji asumsi seperti uji normalitas, uji multikolinieritas dan uji heteroskedastisitas telah dilakukan sebelumnya dan hasilnya menunjukan semua uji asumsi sudah terpenuhi. Pengujian dalam penelitian ini menggunakan program SPSS. Taraf signifikansi yang digunakan dalam penelitian ini adalah 0,05.

Pengujian untuk analis data dilakukan dengan pembagian menjadi 3 model yaitu model 1 untuk menguji hipotesis pertama yaitu pengaruh positif antara brand awareness terhadap brand equity, model 2 untuk menguji hipotesis kedua yaitu untuk pengaruh positif antara brand image terhadap brand equity, model 3 untuk menguji hipotesis ketiga yaitu pengaruh positif antara brand loyalty terhadap brand equity.

\section{ANALISA DAN PEMBAHASAN}

Tabel 2. Hasil Pengujian Hipotesis

\begin{tabular}{|c|l|c|c|c|c|}
\hline & \multicolumn{1}{|c|}{ Hipotesis } & B & Sig & t & Kesimpulan \\
\hline H1 & $\begin{array}{l}\text { Terdapat pengaruh positif } \\
\text { Brand Awareness terhadap } \\
\text { Brand Equity pada pengguna } \\
\text { sepatu Nike di Jakarta. }\end{array}$ & 0,197 & 0,000 & 3,612 & Tidak Ditolak \\
\hline H2 & $\begin{array}{l}\text { Terdapat pengaruh positif } \\
\text { Brand Image terhadap Brand } \\
\text { Equity pada pengguna sepatu } \\
\text { Nike di Jakarta. }\end{array}$ & 0,231 & 0,004 & 2,941 & Tidak Ditolak \\
\hline H3 & $\begin{array}{l}\text { Terdapat pengaruh positif } \\
\text { Brand Loyalty terhadap } \\
\text { Brand Equity pada pengguna } \\
\text { sepatu Nike di Jakarta. }\end{array}$ & 0,539 & 0,000 & 7,596 & Tidak Ditolak \\
\hline
\end{tabular}

Tabel 2 merupakan hasil regresi brand awareness, brand image, dan brand loyalty terhdap brand equity, penelitian ini mempunyai model persamaan regresi sebagai berikut: $\mathrm{BE}$ $=0,160+0,197 \mathrm{BA}+0,231 \mathrm{BI}+0,539 \mathrm{BL}$.

Berdasarkan hasil pengujian hipotesis pada model 1, dapat disimpulkan bahwa brand awareness berpengaruh positif terhadap brand equity. Hipotesis 1 ini sesuai dengan penelitian Muhammad Asif et al. (2015) mengemukakan bahwa brand awareness mempunyai pengaruh yang positif terhadap brand equity, dimana pada penelitian ini juga menunjukkan bahwa kesadaran konsumen terhadap merek tertentu mempunyai dampak yang positif pada brand equity. 
Hipotesis kedua (model 2) digunakan untuk menguji apakah brand image berpengaruh positif terhadap brand equity. Berdasarkan rekapitulasi hipotesis diatas juga diketahui bahwa brand image secara positif mempengaruhi brand equituy dan brand image juga menjadi faktor kedua yang mempengaruhi brand equity. Hipotesis kedua ini juga sesuai dengan penelitian penelitian yang dilakukan. Hipotesis kedua sudah sesuai dengan penelitian Lee et al. (2011) juga menemukan bahwa sebuah perusahaan dapat meningkatkan brand equity dengan meningkatkan brand image perusahaan menjadi brand yang lebih baik.

Hipotesis ketiga (model 3) digunakan unutk menguji apakah brand loyalty berpengaruh positif terhadap brand equity. Hasil penelitian menunjukkan brand loyalty berpengaruh secara positif terhadap brand equity dan juga pada penelitian ini brand loyalty menjadi faktor utama yang mempengaruhi brand equity. Hipotesis ketiga ini sudah sesuai dengan penelitian sebelumnya yang diteliti oleh Torres et. al. (2015) yang juga menunjukkan adanya hubungan yang sangat kuat antara brand loyalty dalam mempengaruhi brand equity, penelitian ini juga menemukan bahwa dalam meningkatkan brand equity perusahaan harus memfokuskan pada brand loyalty.

Uji-F pada penelitian ini adalah variabel brand awareness, brand image, dan brand loyalty akan diuji terhadap variabel brand equity. Hasil uji-F pada penelitian ini mempunyai tingkat signifikansi sebesar 0,000 yang menunjukkan bahwa paling sedikit terdapat satu variabel yang mempengaruhi brand equity. Nilai R-Square pada penelitian ini adalah sebesar 0,571 yang berarti 57,1\% variabel brand equity dapat dijelaskan oleh brand awareness, brand image, dan brand loyalty sedangkan sisanya $(100 \%-57,1 \%)=42,9 \%$ akan dijelaskan oleh variabel-variabel lain yang tidak termasuk pada penelitian ini.

Berdasarkan hasil diatas, maka selutuh hipotesis dalam penelitian ini teruji dengan adanya data secara empiris. Dengan demikian, maka brand equity dapat dipengaruhi oleh brand awareness, brand image dan brand loyalty sepatu Nike.

\section{Kesimpulan dan Saran}

Kesimpulan. Dalam meningkatkan brand equity, salah satu faktor terpenting adalah meningkatkan brand loyalty. Semakin kuat brand loyalty akan mambuat brand equity semakin kuat karena konsumen yang loyal cenderung tidak akan berpindah ke brand lain. Dengan selalu menjaga kualitas produk, terus berinovasi dan selalu menjaga hubungan baik dengan konsumen dapat meningkatkan brand loyalty. Tidak hanya mengandalkan brand loyalty dalam meningkatkan brand equity, tepati perlu ada faktor lain seperti brand awareness dan brand image yang secara signifikan juga berpengaruh positif terhadap brand equity.

Saran. Peneliti menyarankan agar perusahaan sepatu Nike memperhatikan faktor brand awareness dalam penentuan strategi pemasarannya dengan selalu mengeluarkan produk baru secara berkala dan secara rutin memasang iklan agar konsumen sadar akan keberadaan sepatu Nike. Tidak kalah pentingnya, perusahaan sepatu Nike juga harus meningkatkan faktor brand image sepatu Nike dengan selalu bekerjasama dengan atlit-atlit, aktor atau artis yang dapat membangun citra yang baik untuk brand sepatu Nike dan perusahaan sepatu Nike harus tetap mempertahankan faktor brand loyalty dengan selalu menjaga kualitas produk, selalu berinovasi dan menjaga hubungan baik dengan konsumen pengguna sepatu Nike.

\section{DAFTAR PUSTAKA}

Aaker, D.A. (1991). Managing Brand Equity: Capitalizing on the Value of a Brand Name. New York: The Free Press.

Aaker, D. A., \& Joachimsthaler, E. (2000). Brand Leadership. New York: The Free Press 
Asif, M., Abbas, K., Kashif, M., Hussain, S., \& Hussain, I., (2015). Impact of Brand Awareness and Loyalty on Brand Equity. Journal of Marketing and Consumer International Peer, 12, 67-72

Astuti, S.W., \& Cahyadi, I.G. (2007). Pengaruh Elemen Ekuitas Merek terhadap Rasa Percaya Diri Pelanggan di Surabaya Atas Keputusan Pembelian Sepeda Motor Honda. Jurnal Ekonomi dan Bisnis Airlangga, 17(2), 145-156

Dekimpe, M. G., Steenkamp, J. B. E., Mellens, M., \& Abeele, P. V. (1997). Decline and variability in brand loyalty. International Journal of Research in Marketing, 14(5), 405-420

Durianto, D., Sugiarto \& Sitinjak, T. (2004). Strategi Menaklukan Pasar melalui Riset. Ekuisitas dan Prilaku Merek. Jakarta: Gramedia

(2004). Brand Equity Ten: Strategi Memimpin Pasar, Jakarta: PT. Gramedia Pustaka Utama

Feldwick, P. (2005). Defining a Brand in Understanding Brands. London: Kogan Page

Kahle, L. R. \& Kim, CH. (2006). Creating Images and the Psychology of Marketing Communication. New Jersey: LEA

Keller, K. L. (1993). How to manage brand equity. Jakarta: Gramedia Pustaka.

Kotler, P. (2001). A framework for marketing management. New Jersey: Prentice-Hall. ,P. (2009). Marketing Management. U.S.A: Pearson Prentice Hall.

Lee, H.M., Lee, C.C., \& Wu, C.C. (2011). Brand image strategy affects brand equity after M\&A. European Journal of Marketing, 45(7/8), 1091-1111.

Low, G.S \& Lamb, Ch.W. (2000). The Measurement And Dimensionality of Brand Association. Journal of Product and Brand Management, 9, 350-368.

Mowen, J.C, Minor.M. (1995). Consumer Behavior. New York: Prentice Hall Inc.

Rangkuti, F. (2009). The Power of Brands. Jakarta: Gramedia Pustaka Utama.

Rios, R.E., \& Riquelme, H.E. (2008). Brand equity for online companies. Marketing Intelligence \& Planning, 26(7), 719-742.

Rochaety, E. \& Tresnati, R. (2005). Kamus Istilah Ekonomi. Jakarta: PT. Bumi Aksara.

Sasmita, J., \& Suki, N.M. (2015). Young consumers' insights on brand equity: Effects of brand association, brand loyalty, brand awareness, and brand image. International Journal of Retail \& Distribution Management, 43(3), 276-292.

Saveri, E., \& Ling K.C. (2013). The Mediating Effects of Brand Association, Brand Loyalty, Brand Image and Perceived Quality on Brand Equity. Asian Social Science, 9(3), 125137.

Setiadi, N.J. (2003). Perilaku Konsumen: Konsep dan Implikasi untuk Strategi dan Penelitian Pemasaran. Jakarta: Prenada Media.

Simamora, B. (2003). Aura Merek: 7 Langkah Membangun Merek yang Kuat. Jakarta: Gramedia Pustaka.

Supranto, J. \& Limakrisna, H.N. (2007). Perilaku Konsumen dan Strategi Pemasaran untuk Memenangkan Persaingan Bisnis. Jakarta: Mitra Wacana Media.

Tjiptono, F. (2004). Manajemen Jasa. Edisi Pertama. Yogyakarta: Andi Offset.

Torres, P.M., Augusto, G.M., \& Lisboa, J.V. (2015). Determining the causal relationship that affect consumer-based brand equity. Marketing Intelligence \& Planning, 33(6), 944956.

Zaltman, G. \& Wallendorf, M. (1979). Consumer Behavior (2nd Edition). New Jersey: Prentice Hall 
